\title{
Entre a rua e o abrigo: reorganizaçáo do cotidiano ${ }^{1}$
}

\author{
Flávia Barbosa de Oliveira ${ }^{a}$, Samira Lima da Costa ${ }^{b}$ \\ aCentro de Atenção Psicossocial de Concórdia - CAPS, Concórdia, SC, Brasil.

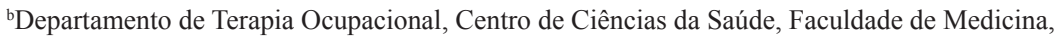 \\ Universidade Federal do Rio de Janeiro - UFRJ, Rio de Janeiro, RJ, Brasil.
}

\begin{abstract}
Resumo: A população em situação de rua tem se mostrado um fenômeno urbano crescente, se transformando em objeto de interesse de gestores públicos e da academia. O texto apresenta os resultados da pesquisa que teve como objetivo compreender o contexto de moradores em situação de rua em atual acolhimento institucional provisório, analisando por que as ruas se tornaram a moradia para algumas pessoas; como ocorreu o processo de elaboração e adaptação das atividades cotidianas nessa nova realidade; quando e por que buscaram sair da rua e como ocorreu esse processo de produção de um novo cotidiano, a partir do acolhimento institucional; como organizam e planejam sua saída do serviço de acolhimento. Para tanto, foram realizadas entrevistas abertas e produção de narrativas de histórias de vida com sete moradores de um serviço de acolhimento institucional, acompanhadas de observação participante durante um ano no mesmo serviço, quando funcionários, moradores e a dinâmica institucional foram observados sistematicamente. Os resultados apontam que os usuários desse serviço passaram por diferentes trajetórias de vida, com um traço em comum: a fragilização crescente dos vínculos e de poder aquisitivo. O serviço parece contribuir para o movimento de saída das ruas, oferecendo acolhimento imediato, acolhimento e autonomia funcional. Entretanto, o movimento de saída do abrigo - que implicaria em outras autonomias, construção de suportes sociais e assistência integrada - aparece nas histórias de vida como um processo difícil e com pouco suporte institucional. O trabalho evidencia a necessidade de se construir debates e proposições acerca do processo de desabrigamento.
\end{abstract}

Palavras-chave: Terapia Ocupacional, Resiliência, Sem-Teto, Abrigo Temporário.

\section{Between the streets and the shelter: everyday reorganization}

\begin{abstract}
The street situation population has been shown as a growing urban phenomenon, becoming an object of interest to public managers and academics. This paper presents the results of a research aimed at understanding the context of street situation residents, under current provisory institutional shelter care, analyzing why the streets have become the home for some people; how the process of development and adaptation of daily activities in this new reality occurred; when and why they decided to leave the streets and how this process of production of a new daily life occurred since the institutional care; and how they organize and plan their departure from the host service. To this end, open interviews and production of narratives of life stories were conducted with seven residents of an institutional shelter care, along with participant observation for one year in the same service, where staff, residents and institutional dynamics were systematically observed. The results show that the users of this service have gone through different paths in life, with a trace in common: the growing weakening of bonds and purchasing power. The service seems to contribute to the movement of departure from the streets and provides immediate host, welcoming and functional autonomy. However, the departure movement from the shelter - that would provide other autonomies, development of social supports and integrated assistance - appears in the life stories as a difficult process with little institutional support. This work highlights the need to build debates and proposals on the homelessness process.
\end{abstract}

Keywords: Occupational Therapy, Resilience, Homeless, Temporary Housing.

Autor para correspondência: Flávia Barbosa de Oliveira, Centro de Atenção Psicossocial de Concórdia, Rua Arciso Colla, 416, CEP 89700-000, Concórdia, SC, Brasil, e-mail: flavinhabandmanu@yahoo.com.br

Recebido em Set. 1, 2014; $1^{\mathrm{a}}$ Revisão em Jan. 19, 2015; Aceito em Fev. 11, 2015. 


\section{Contextualização da pesquisa: população em situação de rua na cidade de Santos, SP}

Este texto apresenta parte das discussóes suscitadas a partir da pesquisa intitulada Reconstruindo o cotidiano: A rua não mais como morada ${ }^{2}$, realizada na cidade de Santos, litoral de São Paulo. A pesquisa buscou compreender o contexto de moradores em situação de rua em atual acolhimento institucional provisório, analisando: por que as ruas se tornaram a moradia para algumas pessoas; como ocorreu o processo de elaboração e adaptação das atividades cotidianas nessa nova realidade; quando e por que buscaram sair da rua e como ocorreu esse processo de produção de um novo cotidiano. Nessa perspectiva, pretende-se identificar as transformaçôes na realização de suas atividades cotidianas a partir de dois eventos ocorridos na vida dessas pessoas: a) ao assumir a rua como morada; e b) ao mudar-se para a situação de acolhimento institucional.

São poucas as pesquisas que retratam características da população em situação de rua com abrangência nacional. Segundo a Coordenadoria de Proteçáo Social Especial em População de Rua e Idoso, na cidade de Santos, em 2009, eram 388 os moradores em situação de rua, sendo 20,5\% nascidos em Santos. Ainda de acordo com a SEAS, 54,9\% têm entre 30 e 49 anos, grande parte, $28,6 \%$, sobrevive como catador e os principais motivos levantados por estarem na rua são: desemprego (17,7\%), problemas familiares $(16,4 \%)$, alcoolismo e drogas $(16 \%)$ e a perda de moradia (12,4\%) (SANTOS, 2009).

Também em 2009 o Ministério do Desenvolvimento Social realizou uma pesquisa em 71 municípios. Foram identificadas 31.922 pessoas em situação de rua nas cidades pesquisadas (BRASIL, 2008).

A rede pública de albergamento e de assistência que se instalou nos últimos anos está definindo os contornos dos circuitos mais adotados pela população de rua que circula entre as cidades, pois a implantaçấo de albergues interfere no nomadismo dessa população, estimulando a sua mobilidade por um lado e facilitando sua fixação nos grandes centros por outro (VARANDA; ADORNO, 2004).

Apenas uma parcela da população em situação de rua, quando vê necessidade, frequenta os abrigos e albergues disponíveis na rede de Assistência Social onde, na maioria das vezes, há uma oferta de leito, roupa de cama, cobertores, roupa para trocar, material de higiene e alimentaçáo. Entretanto, diante das regras estabelecidas nos serviços de acolhimento institucional em função da necessidade de organização e convivência, parte dessa população deixa de frequentar os albergues (COSTA, 2005).

O acolhimento institucional é um Serviço de Proteção Social Especial de Alta Complexidade oferecido pelo SUAS (Sistema Único de Assistência Social). O serviço de acolhimento institucional para adultos e famílias em situação de rua tem como alguns de seus objetivos: restabelecer vínculos familiares e /ou sociais; promover acesso à rede socioassistencial, aos demais órgãos do Sistema de Garantia de Direitos e às demais políticas públicas setoriais; favorecer o surgimento e o desenvolvimento de aptidóes, capacidades e oportunidades para que os indivíduos façam escolhas com autonomia; promover o acesso a programaçóes culturais, de lazer, de esporte e ocupacionais internas e externas, relacionando-as a interesses, vivências, desejos e possibilidades do público; desenvolver condiçôes para a independência e o autocuidado e promover o acesso à rede de qualificação e requalificação profissional com vistas à inclusão produtiva (BRASIL, 2009).

De acordo com a Pesquisa Nacional sobre Populaçáo em Situação de Rua, dos 31.922 moradores em situação de rua no país, $22,1 \%$ costumam dormir em albergues ou outras instituiçôes, 8,3\% alternam, ou seja, ora dormem na rua, ora dormem no abrigo e $69,6 \%$ costumam dormir na rua. Um número muito grande de pessoas em situação de rua não utiliza o serviço de acolhimento institucional do Sistema Único de Assistência Social - SUAS.

\section{População em situação de rua: da vulnerabilidade à desfiliação social}

A população em situação de rua pode ser definida como um grupo populacional heterogêneo, composto por pessoas com diferentes realidades, que têm em comum a condição de pobreza absoluta, a falta de vinculaçáo com o mercado formal e o fato de, com o tempo e por diferentes motivos, terem passado a utilizar o espaço da rua como sobrevivência e moradia (COSTA, 2005). "A falta de convivência com o grupo familiar e a precariedade de outras referências de apoio afetivo e social fazem com que esses indivíduos se encontrem, de certa maneira, impedidos até de resgatarem uma imagem positiva de si mesmos" (VIEIRA et al., 2004, p. 155).

As representaçóes sociais sobre as pessoas em situaçáo de rua reforçam a construção de identidades articuladas com valores negativamente afirmados. Essa população é, sob a óptica do trabalho, frequentemente 
considerada como improdutiva, inútil e preguiçosa (MATTOS; FERREIRA, 2004).

Castel (1993 apud COSTA, 2005) denomina "sobrantes" os indivíduos que foram considerados inválidos pela conjuntura econômica e social. Como não participam do processo de circulaçáo de mercadorias, simplesmente sobram. Nesse contexto, pode-se incluir a população em situação de rua.

A exclusão é um processo de perdas não apenas materiais, mas também afetivas, que coloca os que não produzem, os "sobrantes", na beira da sociedade capitalista. São necessárias medidas públicas que reconheçam essa população e busquem identificá-la pelo que produz, e não pelo que nela falta ou está ausente.

Robert Castel (CASTEL, 1993) aborda o processo de ruptura de redes a partir dos eixos da integração/não integração em dois vieses: no trabalho e na rede de sociabilidade. O processo de ruptura inicia-se quando ocorre uma fragilização das redes sociais de suporte, levando ao isolamento do sujeito, ou a perda econômica, que leva à privação. A respeito dos conceitos de Castel, as autoras Barros, Lopes e Galheigo (2007, p. 348) explicam que “[...] quando um dos eixos começa a se fragilizar, fala-se em vulnerabilidade, e quando ambos se rompem, fala-se em desfiliação".

Considerando possíveis rompimentos tanto em suas relaçóes sociais quanto de trabalho, o morador em situação de rua transita ora na zona de vulnerabilidade, ora em processos de desfiliação. A história de vida do morador em situaçáo de rua deve, portanto, ser estudada e compreendida levando em consideração como são construídas suas relaçóes, como percebe suas atividades cotidianas, caracterizando o convívio social que lhe dá suporte, tanto financeiro como afetivo.

No que se refere ao campo da saúde, segundo Varanda e Adorno (2004), raramente os moradores em situação de rua procuram o serviço especializado, recorrendo à rede ambulatorial em último caso, o que ocasiona o acúmulo de vários problemas de saúde, característicos da situação de exclusão social. De acordo com os dados da pesquisa do Ministério do Desenvolvimento Social (BRASIL, 2008) entre os problemas de saúde mais citados estão: hipertensão $(10,1 \%)$, problemas psiquiátricos/mentais $(6,1 \%)$ e HIV/Aids (5,1\%), sendo que $18,7 \%$ fazem uso de algum medicamento e grande parte $(48,6 \%)$ procura pelos postos/centros de saúde para conseguir os remédios.

Hoje, a população de rua é parte do cenário urbano. Para Adorno e Varanda (2004), passar a residir nas ruas significa desenvolver um processo compensatório em relaçóes às perdas e começar a usar outros recursos de sobrevivência, até então ignorados, assimilando novas formas de organização que permitem a satisfação das necessidades e a superação de obstáculos que a cidade apresenta. $\mathrm{Ou}$ seja, o morador em situação de rua precisa passar por um processo de adaptação à sua nova realidade, de forma que consiga realizar as suas atividades de vida diária, aprender a lidar com perdas, tanto afetivas quanto materiais, e transformar cada rua da cidade em um lugar para se viver.

Entretanto, em muitos municípios brasileiros são oferecidos como alternativa à situação de rua serviços de acolhimento institucional, pertencentes às secretarias municipais ou a Organizaçôes do Terceiro Setor vinculadas à Política Nacional de Assistência Social. Em Santos, a condição de acolhimento institucional é oferecida pela SEAS - Secretaria Municipal de Assistência Social — e por grupos e organizações filantrópicas. Nos serviços da prefeitura, essa condição é oferecida pela Seção Abrigo Provisório de População em Situação de Rua ${ }^{3}$. Como explicitado no próprio nome, nessa seção a permanência é provisória, uma vez que as políticas apontam para o acolhimento institucional como parte do suporte inicial, devendo ser seguido por eventos de resgate de redes ou produçáo de novas redes sociais e de inclusão social no mercado de trabalho.

\section{Cotidiano e Terapia Ocupacional Social}

A Terapia Ocupacional trabalha com foco nas construções do cotidiano a partir das quais as potências e as vulnerabilidades dos sujeitos e coletivos se manifestam. Para a Terapia Ocupacional Social, interessa acompanhar e compreender as formas como se organizam e se desorganizam tais cotidianos, analisando as possibilidades e estratégias aí produzidas.

Para Certeau (2008, p. 31), “[...] o cotidiano é aquilo que nos é dado a cada dia. Todo dia, pela manhã, aquilo que assumimos, ao despertar, é o peso da vida, a dificuldade de viver". Em Terapia Ocupacional, "[...] o cotidiano não é rotina, não é a simples repetição mecânica de ações que levam a um fazer. O cotidiano é o lugar onde buscamos exercer nossa prática transformadora, é o social; é o contexto em que vivemos" (FRANCISCO, 2005, p. 76).

O modo como realizamos as nossas tarefas, o modo pessoal que colocamos nos nossos afazeres, 
o ritmo da nossa vida, tudo isso está relacionado às nossas cadeias operatórias, que nada mais são do que uma série de funçóes/operaçóes que vamos realizando ao longo da vida. Segundo Perrussi (2004, p. 70), cadeias operatórias são "[...] atos, práticas ou comportamentos determinados por mecanismos profundos (genéticos e cognitivos), que geram adaptações no meio ambiente". Esse autor identifica que, em seres humanos, as cadeias operatórias são produzidas principalmente pela memória e pela adaptaçáo, implicando processos de aprendizagem e transmissão de experiência. Entretanto, algumas situaçóes podem mudar nosso cotidiano, convocando a organizaçáo de novas cadeias operatórias. Passar a ser morador de rua é uma dessas situaçôes.

A atividade cotidiana de uma pessoa é a forma como ela produz e adapta suas cadeias operatórias, desenvolvidas para a garantia de sua sobrevivência, satisfação de suas necessidades e a superaçáo dos obstáculos que o seu modo de vida apresenta. A adaptação de uma pessoa à situação de rua — na qual os vínculos sociais podem ser extremamente frágeis - a faz criar um novo cotidiano, no qual o espaço público se mescla com o espaço privado.

Castro, Lima e Brunello (2001) afirmam que:

[...] a vida cotidiana é a verdadeira essência da substância social. E isso só se constitui porque ela se apresenta como um mundo intersubjetivo, um universo cuja participação ocorre com outros homens. A vida é uma rede de trocas e de relaçóes humanas, portanto, aí o cotidiano se forma e é produzido (CASTRO; LIMA; BRUNELLO, 2001, p. 49).

A fragilização dessas redes de trocas e relaçôes pode levar a diferentes formas de distanciamento e de ruptura.

Dessa forma, a Terapia Ocupacional Social, em seu trabalho junto a pessoas que se encontram em vulnerabilidade social ou em processo de desfiliação - conforme conceituação proposta por Castel (1993) —, tem como principal objetivo "[...] fortalecer as redes sociais de suporte, evitando rupturas trazidas por situaçôes nas quais a vulnerabilidade está presente" (BARROS; LOPES; GALHEIGO, 2007, p. 357).

Ao criar propostas de atuação junto à população cujas maiores necessidades configuram-se por sua condição de limitado acesso aos bens sociais e cuja problemática se manifesta pelo agravamento das condições de vida a que está submetida, a Terapia Ocupacional Social investe em conhecer a constituição subjetiva desses sujeitos, que se define "[...] como resultante de um complexo de componentes, como território, história, família, ambiente, os segmentos sociais, o próprio corpo biológico e as classes sociais" (NETO apud GALHEIGO, 2005, p. 33).

\section{Caracterização do campo e Métodos}

O local escolhido para esta pesquisa foi o Abrigo Provisório para População em Situação de Rua, equipamento da Secretaria Municipal de Assistência Social de Santos, localizado no centro de Santos, SP. A Secretaria Municipal de Assistência Social do município autorizou a sua realização. A região do centro atualmente concentra a maior parte da populaçáo em situaçáo de rua da cidade, bem como a maior parte dos equipamentos que atendem a essa populaçáo.

O abrigo provisório em questão recebe diferentes grupos populacionais, sendo caracterizado tanto por pessoas que viveram em situação de rua quanto por pessoas que, por diferentes circunstâncias, encontram-se desabrigadas. $\mathrm{O}$ abrigo oferece moradia para pessoas de ambos os sexos, maiores de 18 anos, com vivência de rua, que necessitam de um tempo de abrigamento para planejarem sua vida e reorganizarem suas atividades cotidianas.

Nessa pesquisa foram entrevistados aqueles que tiveram experiência de rua e concordaram em participar da investigação. Para tanto, os métodos utilizados foram a observaçáo participante e a entrevista aberta, com narrativas de histórias de vida (BECKER, 1999). Durante um ano foi feita observação participante em um abrigo provisório para população em situação de rua. Nesse período, os funcionários, os moradores e a dinâmica desse abrigo foram observados sistematicamente. Além disso, sete moradores que concordaram em participar da pesquisa tiveram sua rotina acompanhada e foram entrevistados. Para todos eles, a pesquisa foi explicada e foi apresentado o Termo de Consentimento Livre e Esclarecido - TCLE, tendo o mesmo sido assinado por todos participantes.

O grupo entrevistado tinha entre 31 e 63 anos, tendo apresentado grande diversidade de tempo e experiência de rua, variando entre 2 meses e 19 anos. A maioria dos entrevistados foi do gênero masculino.

\subsection{Motivos de irem para as ruas}

Confirmando pesquisas anteriores, nessa pesquisa a maior parte da população investigada é do gênero masculino. De acordo com a Pesquisa Nacional 
sobre a População de Rua (BRASIL, 2008), a populaçáo em situação de rua é predominantemente masculina (82\%). A maioria dos entrevistados no Abrigo Provisório também era de homens (aproximadamente $71 \%$ ). A população de rua é basicamente masculina, composta principalmente por homens sós. Trata-se, portanto, de pessoas que não possuem uma convivência permanente com o grupo familiar. Para esses, as relaçóes familiares não estão oferecendo alternativa de acolhimento e abrigo (VIEIRA; BEZERRA; ROSA, 2004). As mulheres possuem uma rede social de suporte maior e estabelecem relaçôes interpessoais mais profundas em comparação aos homens (LOPES; BORBA; REIS, 2003). As mulheres são diferentes dos homens porque no centro de sua existência estão outros valores: a ênfase do relacionamento interpessoal, a atençáo e o cuidado com o outro, a proteção da vida, a valorização da intimidade e do afetivo e a gratuidade das relaçóes (OLIVEIRA, 1992 apud LOPES; BORBA; REIS, 2003).

Os usuários entrevistados apontam dois motivos centrais para terem ido morar nas ruas, sendo o principal deles a situação socioeconômica, seguida pelos problemas com álcool e drogas.

O desemprego, o vício em bebidas alcoólicas e a debilidade física aproximam mais o homem do que a mulher da zona de desfiliação. Os homens entrevistados foram morar nas ruas sozinhos, aos poucos conheceram outros moradores e criaram outras redes de troca. As mulheres ao contrário, foram para as ruas junto com seus companheiros e permaneceram ao lado deles.

\subsection{Experiências de vida}

A partir das entrevistas (estruturadas e semiestruturadas) e dos relatos de história de vida foi possível identificar questóes relevantes na vida dos sujeitos participantes da pesquisa, referentes à experiência de rua e à experiência de acolhimento institucional. Essas questôes estão aqui organizadas em novas categorias de análise, agrupadas por núcleos semânticos e de significado: família, abrigo, gênero, autonomia e cotidiano.

\section{a) Contato com a família e grupos de origem}

Através das narrativas de histórias de vida e pelas falas dos entrevistados pode-se identificar um empobrecimento dos suportes relacionais, pois ao mesmo tempo em que têm poucos amigos com os quais possam contar, preferem morar nas ruas a procurar ajuda da família, o que explicitam em sua fala. A ruptura da rede de suporte parece ser um agravante que pode levar o indivíduo a zona de vulnerabilidade e de desfiliação, conforme Castel (1993).

A não constituição de uma família de extensão, o falecimento de parentes próximos e desavenças familiares propiciaram a fragilizaçáo da rede de suporte. A fragilizaçáo dessa rede pode favorecer a ida da pessoa para a rua, como identificam Lopes, Borba e Reis (2003). Além disso, a vulnerabilidade econômica contribui para uma situação de vulnerabilidade.

A fragilidade ou ausência de uma família de origem em muitas situaçóes provoca a formação de outros "projetos familiares", por agrupamento. O indivíduo na rua pode ter duas escolhas: a) se aproximar de outros moradores, fazer parte de um grupo e fazer novas relações sociais com pessoas numa situação parecida, também com um empobrecimento relacional, mas que poderá dar uma proteção, ou b) ficar isolado, não se aproximar de outros moradores, fazendo com que os suportes relacionais fiquem mais frágeis. Dormir em grupo representa segurança, num certo sentido. $\mathrm{O}$ agrupamento pode tornar-se uma estratégia de sobrevivência. Além disso, nos grupos, a pessoa recupera, até certo ponto, sua identidade pessoal e social; ela é aceita na condição de igual, enquanto que, por outros segmentos sociais, é discriminada e inferiorizada (VIEIRA; BEZERRA; ROSA, 2004).

A partir do abrigamento, entretanto, muitos usuários deixam de ter contato com seus grupos de sociabilidade das ruas. A exclusão social é um processo de perdas não apenas material, mas também afetiva. Identificou-se nas falas dos entrevistados que não ocorreu só a perda de uma casa, mas também de vínculos, de relacionamentos afetivos em que a fragilidade relacional de certa forma contribuiu para a ida à rua.

\section{b) O abrigo - Acolhimento institucional}

Os prazos restritos para a permanência e a sistemática de funcionamento e controle, além do caráter disciplinador e repressivo de alguns abrigos, fazem com que muitas pessoas desabrigadas prefiram a rua (VIEIRA; BEZERRA; ROSA, 2004). Cumprir horários, não usar álcool e drogas, não manter relações sexuais, apresentar-se adequadamente, readquirir a condição de planejamento de despesas são desafios que às vezes estão distantes do contexto de quem já está na rua há algum tempo. Nesse campo reside a possibilidade, ainda que pequena, de que as pessoas que vivem situação de rua venham adquirir autonomia (COSTA, 2005). Segundo Mattos e Ferreira (2004), muitas instituiçóes, como os abrigos, criam uma 
dependência institucional e não oferecem condiçôes para essas pessoas criarem sua própria autonomia. Cabe ressaltar que a autonomia é entendida aqui como a capacidade de um indivíduo gerar e transformar normas e ordens para a sua vida, conforme as diversas situaçóes que enfrenta (KINOSHITA, 2001).

Devido à dinâmica administrativa do Abrigo Provisório, os moradores possuem uma escala de limpeza dos quartos, de ajuda na cozinha e na lavanderia, o que pode produzir ou sustentar certa autonomia funcional de alguns usuários, uma vez que a pessoa com boa condição de saúde acaba atuando nessa manutençáo institucional.

Porém, se por um lado o usuário pode desenvolver alguma autonomia funcional, por outro, sua autonomia cidadá torna-se cada vez mais frágil, durante o acolhimento institucional. A pessoa pode perder o controle de alguns aspectos básicos de sua vida, como agendar uma consulta na Unidade Básica, lembrar-se dos horários de sua medicação e ter os remédios sobre sua responsabilidade, escolher os horários de suas refeiçôes, planejar seus horários de saída e chegada à instituição. Isso acaba comprometendo a autonomia socioafetiva do usuário em situaçáo de acolhimento institucional, uma vez que amplia a dependência do usuário com relação à instituiçáo que o abriga

[...] dependentes somos todos; a questão dos usuários é antes uma questão quantitativa: dependem excessivamente de apenas poucas relaçóes/coisas. Essa situação de dependência restrita/restritiva é que diminui a sua autonomia. Somos mais autônomos quanto mais dependentes de tantas mais coisas pudermos ser, pois isso amplia as nossas possibilidades de estabelecer novas normas, novos ordenamentos para a vida. (KINOSHITA, 2001, p. 57).

A pessoa no processo de acolhimento institucional fica dependente quase que exclusivamente da instituição. Poderia ser diferente se a pessoa pudesse ter uma rede social fora do abrigo e autonomia para gerenciá-la (como agendar as próprias consultas médicas, definir os horários de chegada e saída da instituição - o que permitiria, por exemplo, exercer atividades noturnas fora do abrigo - etc.), pois ampliaria seus vínculos externos, sua rede de dependência e geraria uma maior autonomia.

Entende-se, entretanto, que esse não seja um problema apenas do equipamento, mas do modelo de funcionamento da rede, uma vez que as autonomias cotidianas intraequipamento são estimuladas, mas aquelas que dependeriam da rede intersetorial estão frágeis.

\section{c) Instituiçóes e rede de assistência}

Ter conhecimento das instituiçóes assistenciais utilizadas pela população em situação de rua pode auxiliar a traçar um perfil dos serviços utilizados.

Para Adorno e Varanda (2004), passar a viver nas ruas é começar a usar outros recursos de sobrevivência, até então ignorados, assimilando novas formas de organização que permitem a satisfação das necessidades. Viver na rua não significa necessariamente viver sem dinheiro, mas em grande parte significa adquirir o essencial à sobrevivência sem passar pelo mercado. O morador em situação de rua consegue roupas doadas e se serve de uma rede filantrópica que distribui alimentação (VIEIRA; BEZERRA; ROSA, 2004). A maioria dos entrevistados recorreu alguma vez, enquanto estava na rua, a algum serviço assistencialista, seja para conseguir um prato de comida, como para tomar banho, fazer a barba, cortar as unhas ou mesmo para residir por um período.

A totalidade das instituiçóes citadas pelos entrevistados é de caráter religioso, evidenciando a perspectiva assistencial-caritativa de seus serviços. Tal limitação no reconhecimento da rede intersetorial com a qual poderia/deveria contar pode significar, mais uma vez, a fragilidade dos laços entre setores.

Os serviços oferecidos pelo Terceiro Setor e integrantes da rede de assistência sáo compostos principalmente por grupos religiosos - conforme citado pelos usuários entrevistados, ao sustentar o caráter caritativo, perdem de vista pontos importantes do Sistema Único de Assistência Social, referentes ao poder contratual e à promoção de protagonismos, referendados na Conferência Municipal de Assistência Social de Santos de 2009.

Trabalhar dentro da Assistência Social o significado de Protagonismo como elemento central da prática social e educativa, onde o usuário participa de todas as fases dessa prática, desde a elaboração, execução até a avaliação das açôes propostas, inclusive no plano de atendimento familiar e individual, na vida em abrigo, no cumprimento de medidas e outras situaçôes. $\mathrm{O}$ protagonismo estimula a participaçáo social das pessoas, contribui para a formação de pessoas mais autônomas e comprometidas socialmente com valores de solidariedade e respeito mais incorporados, o que contribui para uma proposta de transformação social. O protagonismo é uma forma de reconhecer que a participação das famílias e das pessoas pode gerar 
mudanças decisivas na realidade social, ambiental, cultural e política onde estão inseridas.

Envolver a população atendida pela Assistência Social em processos de discussão, tomada de decisão, propor e executar ações, visando, através do seu envolvimento na solução de problemas reais (quer da sua vida, da sua família, do seu abrigo, do seu grupo, etc.), desenvolver o seu potencial criativo e a sua força transformadora. (CONSELHO..., 2009, p. 16).

Os equipamentos públicos também foram citados, principalmente para resolução de questôes práticas (documentação, cortar o cabelo etc.) e nos casos de problemas de saúde. Já os equipamentos de passagem são referidos, na maior parte das vezes, como espaço nos quais se vivem experiências bastante desagradáveis, sendo, portanto, pouco procurados.

\section{d) Cotidiano}

Passar a residir nas ruas é não ter mais uma grande preocupação com horários, a não ser para ir às instituiçôes assistencialistas, onde existem horários fixos para a realização de higiene e a doação de alimentos. Pelas respostas dos participantes, não havia a preocupação com os dias da semana, meses, estaçóes do ano. Pode-se perceber que reconhecem na rotina das ruas um cotidiano mais livre, com mais liberdade de tempo.

Tornar-se um morador de rua é mudar aos poucos as cadeias operatórias ${ }^{4}$, pois se modificam o ritmo e os lugares de realização das atividades de vida diária, mudam as pessoas da convivência, a pessoa recebe a alimentação, não sendo mais necessário cozinhar, em alguns momentos tem que aprender a dividir o espaço público com outros moradores, em outros momentos pode optar pela solidão.

Quando se retira da rua e vai morar no abrigo, ocorre outra mudança, tanto nas cadeias operatórias quanto no cotidiano. Começa a ter horários; divide um espaço mais privado com outros moradores; se tiver condiçóes físicas, auxilia na rotina de limpeza do abrigo e deve respeitar horários de chegada, das refeiçóes e de entrada no abrigo. Caso tenha complicações de saúde, deve passar pelas consultas médicas, o que não se fazia com tanta frequência na rua; precisa deixar a prática de sexo; deve abandonar os vícios (alcoolismo e drogas), ainda que não encontre suporte na rede de saúde para tal processo. Talvez por causa dessa mudança no cotidiano, em que deve seguir uma rotina, de certa forma imposta, alguns moradores em situação de rua se recusam a deixar os espaços públicos e a ir a um abrigo.

\section{e) A resiliência}

Considerando que as variáveis ao conceito de resiliência são: o suporte e a rede social, a autoestima, o nível de satisfação, a superação e a transformação de projetos pessoais (TEDESCO; LIBERMAN, 2008), poucas foram encontradas nas falas dos entrevistados. A pessoa que reside na rua e depois utiliza um serviço de acolhimento institucional pode apresentar dificuldades para organizar e reestruturar sua vida diante de situaçóes tão complexas como é a experiência de viver na rua. O serviço de acolhimento institucional tem um papel fundamental no sentido de trabalhar o ex-morador de rua para ele retornar a fazer projetos de vida e ser reinserido socialmente.

\section{Discussão e considerações}

De acordo com o Sistema Único de Assistência Social, os programas de acolhimento e abrigamento para pessoas em situação de rua, devem oferecer proteção às situaçóes de violência, contribuir na construção de autonomia e da inserção social (BRASIL, 2009).

Nesse sentido, o acolhimento institucional de pessoas em situação de rua é como sugerido e implantado pela SEAS necessariamente um espaço de permanência provisória, de forma que sua equipe acompanha o usuário em duas etapas, delimitadas em dois grandes objetivos: a entrada do usuário e sua permanência, através da oferta de acolhimento e produção de autonomias funcionais; e a saída do usuário do equipamento, através de sua inserção em cenários comunitários.

Entende-se, assim, que o primeiro objetivo dos equipamentos de acolhimento institucional seja oferecer acolhimento e garantia de direitos básicos: moradia, alimentação, vestuário, atenção em saúde, permanência em família etc., correspondendo às características da Proteção Social Especial de Alta Complexidade.

Dessa forma, pode-se identificar a partir dos dados da presente pesquisa que o primeiro objetivo vem sendo alcançado, sendo esse o principal motivo pelo qual os entrevistados informam ter se deslocado das ruas para o equipamento.

Entretanto, há na proposta de programas e serviços de abrigamento provisório um segundo objetivo, referente à construção de estratégias para a cidadania plena, na qual o sujeito teria autonomia e poder contratual para as trocas simbólicas (de afeto, renda e conhecimento), favorecendo sua saída do equipamento. 
Esse é um objetivo de difícil alcance, uma vez que seu planejamento é complexo e deve contar com uma forte rede intersetorial que lhe ofereça suporte. Essa passagem das ações que, após garantir proteção especial de alta complexidade caminha para a oferta de proteção social de média complexidade e, em seguida, encaminha o sujeito para a rede de proteçáo social básica, necessita contar com uma forte rede de serviços e equipamentos que promovam tal trajetória do sujeito entre os diferentes níveis de proteção social.

As autonomias funcionais (higiene pessoal, limpeza do ambiente, alimentação etc.) parecem fazer parte do projeto de acolhimento institucional, tanto para facilitar a convivência dentro do equipamento quanto para vincular os usuários a certo modelo de convivência socialmente aceito.

Por outro lado, as autonomias afetivas e sociais, ou seja, as autonomias na produção de novas redes relacionais e de interdependência (KINOSHITA, 2001), implicam em um novo modelo de acolhimento institucional, que produza espaços de expressão e deliberação de questóes relevantes pelo e para o coletivo (incluindo-se o usuário) e que possa contar, incondicionalmente, com a rede e referência e contrarreferência (incluindo-se aí os núcleos de orientação para o trabalho, residenciais terapêuticos, casas de convalescença, centros de reabilitação psicossocial, escolas de tempo integral com acompanhamento das famílias, unidades básicas de saúde de portas abertas aos usuários de seu território, entre outros).

Esse novo modelo de acolhimento institucional, que avança do primeiro para o segundo objetivo (ou seja: avança da entrada do usuário no equipamento e seu acolhimento para a saída do usuário do equipamento e seu acompanhamento), está ainda por ser inventado, não apenas no equipamento pesquisado, mas em todo o território nacional.

A busca de experiências exitosas, os grupos de estudos sobre o tema e o acolhimento aos questionamentos e encaminhamentos das equipes dos serviços podem ser fortes ferramentas de resistência à desmotivaçáo e ao sentimento de impotência frente à difícil e complexa tarefa que se coloca a esses equipamentos.

Considerando as características que definem a atuação do terapeuta ocupacional no campo social, entende-se que esse profissional possa colaborar de forma efetiva com as equipes dos serviços, nos projetos de produção e fortalecimento de redes - tanto sociais quanto intersetoriais, além de poder oferecer importantes contribuiçóes nos programas de reorganização do cotidiano e investimentos em autonomia - tanto funcional quanto relacional.

\section{Referências}

BARROS, D. D.; LOPES, R. E.; GALHEIGO, S. M. Novos espaços, novos sujeitos: a terapia ocupacional territorial e comunitário. In: CAVALCANTI, A.; GALVÃO, C. Terapia Ocupacional: fundamentação e prática. Rio de Janeiro: Guanabara Koogan, 2007. p. 357-358.

BECKER, H. S. Métodos de pesquisa em ciências sociais. 4. ed. São Paulo: HUCITEC, 1999.

BRASIL. Ministério do Desenvolvimento Social e Combate à Fome. Pesquisa nacional sobre a população em situação de rua. Brasília, 2008. Disponível em: <http://www. mds.gov.br>. Acesso em: 8 out. 2009.

BRASIL. Ministério do Desenvolvimento Social e Combate à Fome. Tipificação nacional de serviços socioassistenciais. Texto da Resoluçáo no 109 , de 11 de novembro de 2009. Diário Oficial da Uniâo, Poder Executivo, Brasília, DF, 25 nov. 2009. Disponível em: <http:// aplicacoes.mds.gov.br/snas/documentos/livro\%20Tipificaca $\% 20$ Nacional $\% 20-\% 2020.05 .14 \% 20 \% 28$ ultimas\%20atualizacoes\%29.pdf>. Acesso em: 10 jun. 2010 .

CASTEL, R. Da indigência à exclusão, a desfiliação: precariedade do trabalho e vulnerabilidade relacional. In: LANCETTI, A. (Org.). Saúde loucura. São Paulo: Hucitec, 1993. p. 21-48.

CASTRO, E. D.; LIMA, E. M. F. A.; BRUNELLO, M. I. B. Atividades humanas e Terapia Ocupacional. In: DE CARLO, M. M. R.; BARATALOTTI, C. C. Terapia Ocupacional no Brasil: fundamentos e perspectivas. São Paulo: Plexus, 2001. p. 41-59.

CERTEAU, M. A invenção do cotidiano 2: morar, cozinhar. Petrópolis: Vozes. 2008.

CONSELHO MUNICIPAL DE ASISTÊNCIA SOCIAL - CMAS. Resolução Normativa no 159/2009, de 11 de setembro de 2009. Dispóe acerca da aprovação do relatório final de deliberaçóes e de propostas aprovadas na VII Conferência Municipal de Assistência Social - VIII CMAS. Diário Oficial de Santos, Santos, 11 set. 2009.

COSTA, A. P. M. População em situação de rua: contextualização e caracterização. Textos \& Contextos, Porto Alegre, v. 4, n. 1, p. 1-15, 2005. Disponível em: <http:// revistaseletronicas.pucrs.br/ojs/index.php/fass/article/ viewFile/993/773>. Acesso em: 12 out. 2011.

FRANCISCO, B. R. Terapia Ocupacional. São Paulo: Papirus, 2005.

GALHEIGO, S. M. O social: idas e vindas de um campo de ação em terapia ocupacional. In: PÁDUA, E. M. M.; MAGALHĀES, L. V. Terapia Ocupacional: teoria e prática. Campinas: Papirus, 2005. p. 29-46.

KINOSHITA, R. T. Contratualidade e reabilitação psicossocial. In: PITTA, A. (Org.). Reabilitação Psicossocial no Brasil. São Paulo: HUCITEC, 2001. p. 55-59. 
LOPES, R. E.; BORBA, P. L. O.; REIS, T. A. M. Um olhar sobre as trajetórias, percursos e histórias de mulheres em situação de rua. Cadernos de Terapia Ocupacional da UFSCar, São Carlos, v. 11, n. 1, p. 38-53, 2003.

MATTOS, R. M.; FERREIRA, R. F. Quem vocês pensam que (elas) são? Representaçóes sobre as pessoas em situação de rua. Psicologia e Sociedade, Porto Alegre, v. 16, n. 2, p. 47-58, 2004. http://dx.doi.org/10.1590/ S0102-71822004000200007.

PERRUSSI, A. A técnica na humanização do homo sapiens sapiens: comentários sobre a visão da técnica em Leroi-Gourhan. Politica \& Trabalho: Revista de Ciências Sociais, João Pessoa, n. 21, p. 61-77, 2004.
SANTOS. Divulgado resultado do censo sobre população de rua. Diário Oficial de Santos, Santos, 22 ju. 2009. Disponível em: <www.santos.sp.gov.br>. Acesso em: 8 out. 2009 .

TEDESCO, S.; LIBERMAN, F. O que fazemos quando falamos em vulnerabilidade? O Mundo da Saúde, São Paulo, v. 32, n. 2, p. 254-260, 2008.

VARANDA, W.; ADORNO, R. C. F. Descartáveis urbanos: discutindo a complexidade da população de rua e o desafio para políticas de saúde. Saúde e Sociedade, São Paulo, v. 13, n. 1, p. 56-69, 2004.

VIEIRA, M. A. C.; BEZERRA, E. M. R.; ROSA, C. M. M. População de rua: quem é, como vive, como é vista. São Paulo: Hucitec, 2004.

\section{Contribuição dos Autores}

Flávia Barbosa de Oliveira: Seleção do referencial teórico, realização do trabalho de campo e redação do texto. Samira Lima da Costa: Orientação da pesquisa, análise e discussões, revisão do texto final.

\section{Notas}

${ }^{1}$ A pesquisa foi submetida, avaliada e aprovada pelo Núcleo de Bioética da Universidade Federal de Sáo Paulo (UNIFESP), Campus Baixada Santista, e pelo Comitê de Ética em Pesquisa em Seres Humanos da UNIFESP. Foi também autorizada pela Secretaria de Assistência Social do município de Santos e todos os participantes assinaram seu Termo de Consentimento Livre e Esclarecido.

${ }^{2}$ Pesquisa de Iniciação Científica vinculada ao curso de graduação em Terapia Ocupacional da Universidade Federal de Sáo Paulo - UNIFESP, Campus Baixada Santista, desenvolvida pela primeira autora e orientada pela segunda autora.

${ }^{3}$ Nome do serviço em 2009 e 2010.

${ }^{4}$ Cadeias operatórias são uma série de funçôes/operações que vamos realizando ao longo da vida e que caracterizam a nossa rotina, essa que produzimos através do cotidiano. 